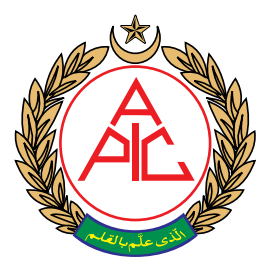

${ }^{1}$ Senior Professor,

${ }^{2}$ Postgraduate Student,

${ }^{3}$ Associate Professor,

Department of Anesthesiology, JLN Medical College \& Hospital, Ajmer, Rajasthan, (India)

Correspondence: Dr. Surendra Kumar Sethi

Flat No. 202, Shiv Enclave, Civil Lines, Ajmer-305001, Rajasthan, (India)

Phone: +919587150598; E-mail: drsurendrasethi80@gmail.com Received: 11 September 2019;

Reviewed: 16, 26 October 2019

27 December 2019, February 2020;

Revised: 26 November 2019, 31 January, 24 February 2020:

Accepted: 29 February 2019

\section{A comparative study between two different doses of oral pregabalin in attenuating hemodynamic response to laryngoscopy and endotracheal intubation}

\author{
Veena Patodi, $\mathrm{MD}^{1}$, Ratan Lal Yadav, $\mathrm{MD}^{2}$, Surendra Kumar Sethi, MD, \\ Neena Jain, $\mathrm{MD}^{1}$, Maina Singh, $\mathrm{MD}^{3}$
}

\begin{abstract}
Background: Laryngoscopy and endotracheal intubation is usually associated with exaggerated haemodynamic response. The aim of our study was to compare and evaluate the efficacy of two different doses of oral pregabalin in attenuating hemodynamic response to laryngoscopy and endotracheal intubation along with preoperative level of sedation.
\end{abstract}

\begin{abstract}
Methodology: This prospective randomized study was conducted on one hundred patients, aged 18 to 55 years of either sex belonging to American Society of Anesthesiologists (ASA) physical status I and II, posted for various elective surgical procedures under general anesthesia. They were randomly allocated into two groups ( Group P1 and Group P2) of 50 patients each by computer generated tables of random numbers. Group P1 and P2 received oral pregabalin $75 \mathrm{mg}$ and $150 \mathrm{mg}$ respectively 1 hour prior to induction of anesthesia. Anesthesia technique was standardized and both groups were assessed for hemodynamic changes (HR, SBP, DBP and MAP) after premedication, before and after induction, immediately after intubation and at the end of $1,3,5,10$ and 15 min after intubation along with preoperative sedation, side effects or complications.
\end{abstract}

\begin{abstract}
Results: The attenuation in mean HR was comparable between two groups $(p>0.05)$, with significant attenuation in SBP, DBP and MAP between two groups. $(p<0.05)$. The preoperative levels of sedation were higher in Group P2 but was statistically insignificant. $(p>0.05)$ None of the patients had experienced any side effects except dizziness.

Conclusion: Oral pregabalin $150 \mathrm{mg}$ when used as a premedication $60 \mathrm{~min}$ prior to induction of anesthesia was found to be more effective than oral pregabalin $75 \mathrm{mg}$ in terms of significant attenuation of hemodynamic pressor response to laryngoscopy and endotracheal intubation with acceptable levels of sedation and minimal side effects.
\end{abstract}

Key words: Pregabalin; Hemodynamic response; Laryngoscopy; Endotracheal intubation

Citation: Patodi V, Yadav RL, Sethi SK, Jain N, Singh M. A comparative study between two different doses of oral pregabalin in attenuating hemodynamic response to laryngoscopy and endotracheal intubation. Anaesth pain intensive care 2020;24(1):2835. DOI: https://doi.org/10.35975/apic.v24i1.1218

\section{INTRODUCTION}

Laryngoscopy and endotracheal intubation are noxious stimuli that cause transient but marked sympathetic response leading to increased plasma catecholamines concentration manifesting as hypertension, tachycardia, arrhythmias, myocardial ischemia and cerebral hemorrhage in normal as well as susceptible individuals. ${ }^{1-4}$ Direct laryngoscopy activates proprioceptors at the base of tongue which augments cervical sympathetic activity in 
efferent fibers to heart along with increased plasma catecholamines concentration in proportion to the magnitude of stimulus leading to arterial hypertension and tachycardia. Subsequent intubation stimulates the receptors in the larynx and trachea with enhancement of sympathetic response. ${ }^{5}$ The rise in blood pressure and heart rate on laryngoscopy and endotracheal intubation is transient, variable and unpredictable.

Several methods and pharmacologic agents have been evaluated for blunting hemodynamic pressor response to airway instrumentation with variable results. These include intubation in a deeper plane of anesthesia and use of drugs e.g. local anesthetics (lidocaine), ${ }^{6}$ opioids, ${ }^{7}$ adrenoceptor blockers, ${ }^{8}$ calcium channel blockers, ${ }^{9}$ vasodilators, ${ }^{10}$ dexmedetomidine ${ }^{11}$ and clonidine. ${ }^{12}$ No single drug or technique has been found to be completely satisfactory.

Pregabalin is a lipophilic gamma-amino-butyric acid (GABA) analogue with anticonvulsant, anxiolytic, analgesic and sleep-modulating properties. It binds to the $\alpha_{2}-\delta$ subunit of presynaptic, voltagedependent calcium channels that are widely distributed throughout the central and peripheral nervous system, resulting in decreased synthesis and release of several neurotransmitters like glutamate, norepinephrine, serotonin, dopamine, and substance P. Pregabalin is well absorbed after oral administration and its oral bioavailability is $90 \%$. Peak plasma concentrations are achieved within 1 to $1.5 \mathrm{~h}$ of oral administration and half-life is approximately $6 \mathrm{~h}$. It undergoes negligible metabolism, approximately $90 \%$ of the administered dose is recovered in the urine as unchanged pregabalin. ${ }^{13}$

Various studies have been done to reduce or abolish this hemodynamic pressor response using pregabalin as a premedication in different doses $(75-300 \mathrm{mg})$ but most of the studies had compared pregabalin with either the placebo or other drugs. A very few studies had compared efficacy of two different doses of pregabalin used as premedication for this purpose. . $^{6-13}$ A higher dose $(300 \mathrm{mg})$ was reported to be associated with increased levels of sedation. ${ }^{14}$ Based on the results of these studies, we chose two different doses of pregabalin, $75 \mathrm{mg}$ and $150 \mathrm{mg}$ for this prospective, double blind, randomized controlled study to compare and evaluate the efficacy in attenuating hemodynamic pressor response to laryngoscopy and endotracheal intubation along with preoperative level of sedation and any significant side effects or complications.

\section{METHODOLOGY}

This prospective, randomized, double blind study was conducted on one hundred adult patients aged 18 to 55 years, of either sex with American Society of Anesthesiologists (ASA) physical status ${ }^{15}$ I and II, posted for various elective surgical procedures under GA after local institutional ethical committee approval and written informed consent. Patients with history of cardiac, pulmonary, liver and renal disease, patients on sedatives, hypnotics, antidepressants, beta blockers or antihypertensive medications, anticipated difficult intubation, hypersensitivity to any anesthetic or study drug, patients weighing $>100$ $\mathrm{kg}$ and pregnant or lactating women were excluded from the study (Figure 1).

All the study participants were randomly allocated into two groups with 50 patients in each group using computer generated tables of random numbers. Group P1 $(\mathrm{n}=50)$ received pregabalin $75 \mathrm{mg}$ and Group P2 $(\mathrm{n}=50)$ received pregabalin $150 \mathrm{mg}$ one hour prior to induction of anesthesia.

Pre-anesthetic evaluation was done on the day before surgery which included relevant patient history, preanesthetic examination and routine investigations. All patients included in the study were kept NPO for a minimum period of 8 hours before surgery. On the day of surgery, in the pre-anesthetic room baseline vital parameters including systolic blood pressure (SBP), diastolic blood pressure (DBP), mean arterial pressure (MAP), heart rate (HR) and oxygen saturation $\left(\mathrm{SpO}_{2}\right)$ were recorded. Thereafter the patients in Group P1 received pregabalin $75 \mathrm{mg}$ and Group P2 received $150 \mathrm{mg}$ with a sip of water, $60 \mathrm{~min}$ before the expected time of induction of anesthesia. The drugs were given by a resident anesthesiologist who was not involved in the study,

The preoperative level of sedation was evaluated just before giving oral tablet and before induction of anesthesia and graded by 6 point Ramsay sedation score (RSS). ${ }^{16}$

On arrival in the operating room, standard ASA monitoring was attached and baseline values of hemodynamic parameters (HR, SBP, DBP, MAP and $\mathrm{SpO}_{2}$ ) were recorded. After securing a $20 \mathrm{G}$ intravenous (iv) cannula, an infusion of crystalloid intravenous fluid (ringer lactate @ 6-8 ml/kg) was started. In premedication, glycopyrrolate $0.05 \mathrm{mg} /$ $\mathrm{kg}$ iv, ondansetron $0.1 \mathrm{mg} / \mathrm{kg}$ iv and tramadol 2 $\mathrm{mg} / \mathrm{kg}$ iv were given. Patients were preoxygenated with $100 \%$ oxygen for 3 min using Bain's circuit, induction was done with propofol $2 \mathrm{mg} / \mathrm{kg}$ iv (calculated on the basis of ideal body weight) till loss of response to verbal commands followed by manual intermittent positive pressure ventilation with $100 \%$ oxygen. The hemodynamic parameters (HR, SBP, DBP and MAP) were again recorded after induction prior to laryngoscopy. After $60 \mathrm{sec}$ of administering succinylcholine $1.5 \mathrm{mg} / \mathrm{kg}$ iv, conventional laryngoscopy (Macintosh blade) and tracheal intubation was performed by an experienced anesthesiologist and accomplished within $20 \mathrm{sec}$ 
(minimal duration) with cuffed endotracheal tube (7.0-7.5 mm ID for females and 8.0-8.5 mm ID for males). In case of unexpected difficult intubation, the patient was excluded from the study.

Anesthesia was maintained with $\mathrm{O}_{2}: \mathrm{N}_{2} \mathrm{O}$ (50:50) and isoflurane (MAC upto 1.4\%) using closed circuit with controlled mechanical ventilation and vecuronium $0.1 \mathrm{mg} / \mathrm{kg}$ loading dose given after return of spontaneous respiration. We aimed to maintain normocapnia ( $\mathrm{EtCO}_{2}$ between 35 to $40 \mathrm{~mm} \mathrm{Hg}$ ). Supplemental neuromuscular blockade was achieved with vecuronium $0.02 \mathrm{mg} / \mathrm{kg}$ to maintain adequate intraoperative muscle relaxation.

Hemodynamic parameters were recorded at 1, 3, 5, 10 and $15 \mathrm{~min}$ after intubation.

Isoflurane was discontinued at the end of surgery and residual neuromuscular block was antagonized with appropriate doses of neostigmine $0.05 \mathrm{mg} /$ $\mathrm{kg}$ and glycopyrrolate $0.01 \mathrm{mg} / \mathrm{kg}$ iv. Patients were extubated after complete recovery from anesthesia with adequate muscle power.

After tracheal extubation and on awakening from anesthesia, patients were shifted to post anesthesia care unit (PACU) and monitored for at least 3 hours or until there were no signs of drug-induced side effects such as nausea, vomiting, respiratory depression or hemodynamic instability in the form of hypotension/

Table 1: Demographic profile in two groups

\begin{tabular}{l|c|c|c}
\multicolumn{1}{c|}{ Parameters } & $\begin{array}{c}\text { Group P1 } \\
(\mathbf{n}=\mathbf{5 0})\end{array}$ & $\begin{array}{c}\text { Group P2 } \\
\mathbf{( n = 5 0 )}\end{array}$ & P value \\
\hline Age (years) & $31.62 \pm 11.37$ & $33.52 \pm 12.05$ & 0.41 \\
\hline Sex (M/F) & $15 / 35$ & $18 / 32$ & 0.52 \\
\hline Weight $(\mathrm{Kg})$ & $53.20 \pm 10.66$ & $53.24 \pm 10.34$ & 0.98 \\
\hline ASA physical status (I/II) & $45 / 5$ & $46 / 4$ & 0.72 \\
\hline${ }^{*}$ Data expressed as Mean $\pm S D$ and number $(n) ; p>0.05$
\end{tabular}

Table 2- Comparison of mean HR (bpm) in two groups

\begin{tabular}{l|c|c|c}
\multicolumn{1}{c|}{ Time interval } & $\begin{array}{c}\text { Group P1 } \\
(\mathbf{n = 5 0 )}\end{array}$ & $\begin{array}{c}\text { Group P2 } \\
\mathbf{( n = 5 0 )}\end{array}$ & $\begin{array}{c}\text { P value } \\
\text { (Intergroup) }\end{array}$ \\
Baseline & $83.46 \pm 10.48$ & $3.04 \pm 9.77$ & 0.42 \\
\hline Before induction & $85.40 \pm 9.23$ & $83.72 \pm 7.49$ & 0.32 \\
\hline After induction & $86.26 \pm 8.68$ & $84.52 \pm 8.08$ & 0.29 \\
\hline Immediately after intubation & $94.64 \pm 8.85$ & $92.16 \pm 7.35$ & 0.13 \\
\hline At 1 min & $95.90 \pm 8.14$ & $93.08 \pm 6.75$ & 0.06 \\
\hline At 3 min & $92.88 \pm 8.21$ & $90.30 \pm 6.36$ & 0.08 \\
\hline At 5 min & $90.62 \pm 8.35$ & $87.98 \pm 6.52$ & 0.08 \\
\hline At 10 min & $84.74 \pm 6.28$ & $82.56 \pm 5.29$ & 0.06 \\
\hline At 15 min & $82.14 \pm 6.29$ & $80.38 \pm 4.75$ & 0.11 \\
\hline *Values expressed as Mean $\pm S D$ & $+P<0.05$ - significant; $P<0.01$ - highly significant
\end{tabular}

hypertension or tachycardia/bradycardia, dizziness, sedation and other side effects.

Tachycardia was defined as heart rate greater than 100 beats/min and bradycardia was defined as heart rate less than 50 beats/min and treated with atropine $(0.01 \mathrm{mg} / \mathrm{kg})$ iv. Hypertension was defined as systolic blood pressure more than $180 \mathrm{mmHg}$, which was managed by increasing the inhaled concentration of volatile anesthetic agent i.e. isoflurane. Hypotension was defined as fall in mean arterial pressure by more than $20 \%$ from baseline, and treated primarily by increasing the intravenous fluid infusion rate and additionally with mephentermine $6 \mathrm{mg}$ iv boluses. Postoperative respiratory depression was defined as $\mathrm{RR}<10 / \mathrm{min}$ and managed by using $100 \%$ oxygen with Bain's circuit and manual assisted ventilation.

Statistical Analysis: Based on a previous study, ${ }^{17}$ a pilot study was conducted before performing this study and the sample size was calculated to be 40 patients in each group with power of $80 \%$ and an $\alpha$ - error 0.05 . By taking HR as the primary objective, assuming the difference in mean heart rate to be 2.6 and standard deviation 4 while considering 10\% loss to follow up, sample size was enhanced and rounded to 50 patients in each group. The numerical data are expressed as mean with a standard deviation and categorical data as numbers and percentages. Statistical analysis was carried out using Microsoft Excel and SPSS software. Categorical data between two groups were compared using Chisquare / Fischer's test. Student's unpaired t-test and repeated measure ANOVA test were used to analyze the quantitative parametric data (numerical data) while non-parametric data were compared using Mann-Whitney $\mathrm{U}$ test. $\mathrm{p}<0.05$ was considered statistically significant and $\mathrm{p}<$ 0.001 as highly significant.

\section{RESULTS}

The demographic profile was found comparable between two groups with respect to mean age, sex, weight, and ASA physical status; $\mathrm{p}>0.05$ (Table 1)

The baseline hemodynamic parameters (HR, SBP, DBP and MAP) were comparable between two groups $(\mathrm{p}>0.05)$. Similarly, before and after induction, HR, SBP, DBP and MAP were comparable in both Groups ( $\mathrm{p}>$ 0.05) (Table 2, 3, 4 \& 5). 
The intergroup comparison showed no significant difference in the HR at all time intervals in both groups $(p>0.05)$. The maximum increase in HR was seen at $1 \mathrm{~min}$ after intubation in both groups. The mean HR returned to their baseline values earlier in Group P2 (Table 2). On inter group comparison, mean SBP before and after induction was comparable in both groups $(\mathrm{p}>0.05)$. It was significantly increased in both groups immediately after intubation, at $1 \mathrm{~min}$ and $3 \mathrm{~min}$ but increase was lesser in Group P2 which was statistically significant $(\mathrm{p}<0.05)$ (Table 3$)$. Similar trends were observed for a change in $\mathrm{DBP}$ and MAP at various time intervals (Table $4 \& 5$ ). The mean SBP, DBP and MAP returned to their baseline values earlier in Group P2 when compared to Group P1.

The RSS just before giving oral tablet was comparable in both the study groups. RSS was higher in Group P2 just before induction but it was statistically non-significant $(p=0.06)$ (Figure 2). No complications occurred after use of oral premedication with pregabalin in our study except dizziness experienced by one patient in Group P1 and 2 patients in Group P2.

\section{DISCUSSION}

Our study aimed to evaluate safe and clinically effective dose of oral pregabalin premedication for attenuation of hemodynamic response to laryngoscopy and endotracheal intubation as well as its sedative effect. The primary objective of our study was to observe hemodynamic response to laryngoscopy and endotracheal intubation while the secondary objectives were to observe preoperative level of sedation and side effects.

In our study, although the increase in HR was found to be insignificant in both groups but the increase in HR was lesser in pregabalin $150 \mathrm{mg}$ group which showed that pregabalin $150 \mathrm{mg}$ provided an adequate anxiolysis and analgesia with acceptable levels of sedation which prevent rise in mean HR during laryngoscopy and endotracheal intubation and immediately thereafter. Our results are in concordance with
Table 3: Intra and intergroup comparison of mean SBP $(\mathrm{mmHg})$ in two groups

\begin{tabular}{l|c|c|c} 
Time interval & $\begin{array}{c}\text { Group P1 } \\
(\mathbf{n}=\mathbf{5 0})\end{array}$ & $\begin{array}{c}\text { Group P2 } \\
\mathbf{( n = 5 0 )}\end{array}$ & $\begin{array}{c}\text { P-Value } \\
\text { (Intergroup) }\end{array}$ \\
\hline Baseline & $122.30 \pm 8.01$ & $121.40 \pm 6.50$ & 0.52 \\
\hline Before induction & $122.90 \pm 7.19$ & $121.60 \pm 5.24$ & 0.30 \\
\hline After induction & $119.70 \pm 6.57$ & $119.30 \pm 5.02$ & 0.78 \\
\hline Immediatelyafter & $133.50 \pm 8.30$ & $128.60 \pm 6.67$ & 0.001 \\
\hline intubation & $129.80 \pm 6.51$ & $126.00 \pm 5.37$ & 0.002 \\
\hline At 1 min & $124.70 \pm 5.57$ & $122.20 \pm 5.08$ & 0.02 \\
\hline At 3 min & $121.60 \pm 5.16$ & $120.10 \pm 4.13$ & 0.11 \\
\hline At 5 min & $119.40 \pm 4.66$ & $118.10 \pm 4.33$ & 0.16 \\
\hline At 10 min & $119.60 \pm 3.48$ & $118.80 \pm 3.15$ & 0.22 \\
\hline At 15 min &
\end{tabular}

*Values expressed as Mean $\pm S D \quad+P<0.05$ - significant; $P<0.01$ - highly significant

Table 4: Intra and intergroup comparison of mean DBP ( $\mathrm{mmHg})$ in two groups

\begin{tabular}{l|c|c|c}
\multicolumn{1}{c|}{ Time interval } & $\begin{array}{c}\text { Group P1 } \\
\mathbf{( n = 5 0 )}\end{array}$ & $\begin{array}{c}\text { Group P2 } \\
\mathbf{( n = 5 0 )}\end{array}$ & $\begin{array}{c}\text { P- Value } \\
\text { (Intergroup) }\end{array}$ \\
\hline Baseline & $79.38 \pm 6.24$ & $78.78 \pm 5.32$ & 0.60 \\
\hline Before induction & $80.52 \pm 5.85$ & $79.08 \pm 4.66$ & 0.17 \\
\hline After induction & $76.98 \pm 5.43$ & $76.62 \pm 4.32$ & 0.71 \\
\hline $\begin{array}{l}\text { Immediately after } \\
\text { intubation }\end{array}$ & $88.08 \pm 6.24$ & $85.70 \pm 4.78$ & 0.03 \\
\hline At 1 min & $84.70 \pm 5.06$ & $82.24 \pm 4.39$ & 0.01 \\
\hline At 3 min & $80.80 \pm 5.07$ & $78.92 \pm 4.17$ & 0.04 \\
\hline At 5 min & $77.42 \pm 4.20$ & $77.10 \pm 3.23$ & 0.67 \\
\hline At 10 min & $76.08 \pm 4.32$ & $75.30 \pm 3.91$ & 0.34 \\
\hline At 15 min & $76.66 \pm 3.57$ & $76.36 \pm 4.10$ & 0.69 \\
\hline
\end{tabular}

*Values expressed as Mean $\pm S D$

$\uparrow P<0.05$ - significant; $P<0.01$ - highly significant

Table 5: Intra and intergroup comparison of MAP $(\mathrm{mmHg})$ in two groups

\begin{tabular}{l|c|c|c}
\multicolumn{1}{c|}{ Time interval } & $\begin{array}{c}\text { Group P1 } \\
(\mathbf{n = 5 0 )}\end{array}$ & $\begin{array}{c}\text { Group P2 } \\
\mathbf{( n = 5 0 )}\end{array}$ & $\begin{array}{c}\text { P-Value } \\
\text { (Intergroup) }\end{array}$ \\
\hline Baseline & $93.92 \pm 6.95$ & $93.10 \pm 5.69$ & 0.52 \\
\hline Before induction & $94.70 \pm 6.32$ & $93.46 \pm 5.55$ & 0.30 \\
\hline After induction & $91.24 \pm 5.71$ & $90.86 \pm 4.45$ & 0.71 \\
\hline $\begin{array}{l}\text { Immediately after } \\
\text { intubation }\end{array}$ & $103.30 \pm 6.69$ & $99.48 \pm 5.37$ & 0.002 \\
\hline At 1 min & $100.00 \pm 5.47$ & $96.68 \pm 4.52$ & 0.001 \\
\hline At 3 min & $95.60 \pm 5.11$ & $93.52 \pm 4.32$ & 0.03 \\
\hline At 5 min & $92.24 \pm 4.40$ & $91.46 \pm 3.41$ & 0.32 \\
\hline At 10 min & $90.30 \pm 3.92$ & $89.94 \pm 4.81$ & 0.68 \\
\hline At 15 min & $90.96 \pm 3.51$ & $90.66 \pm 3.65$ & 0.67 \\
\hline
\end{tabular}

*Values expressed as Mean $\pm S D$

$+P<0.05$ - significant; $P<0.01$ - highly significant 


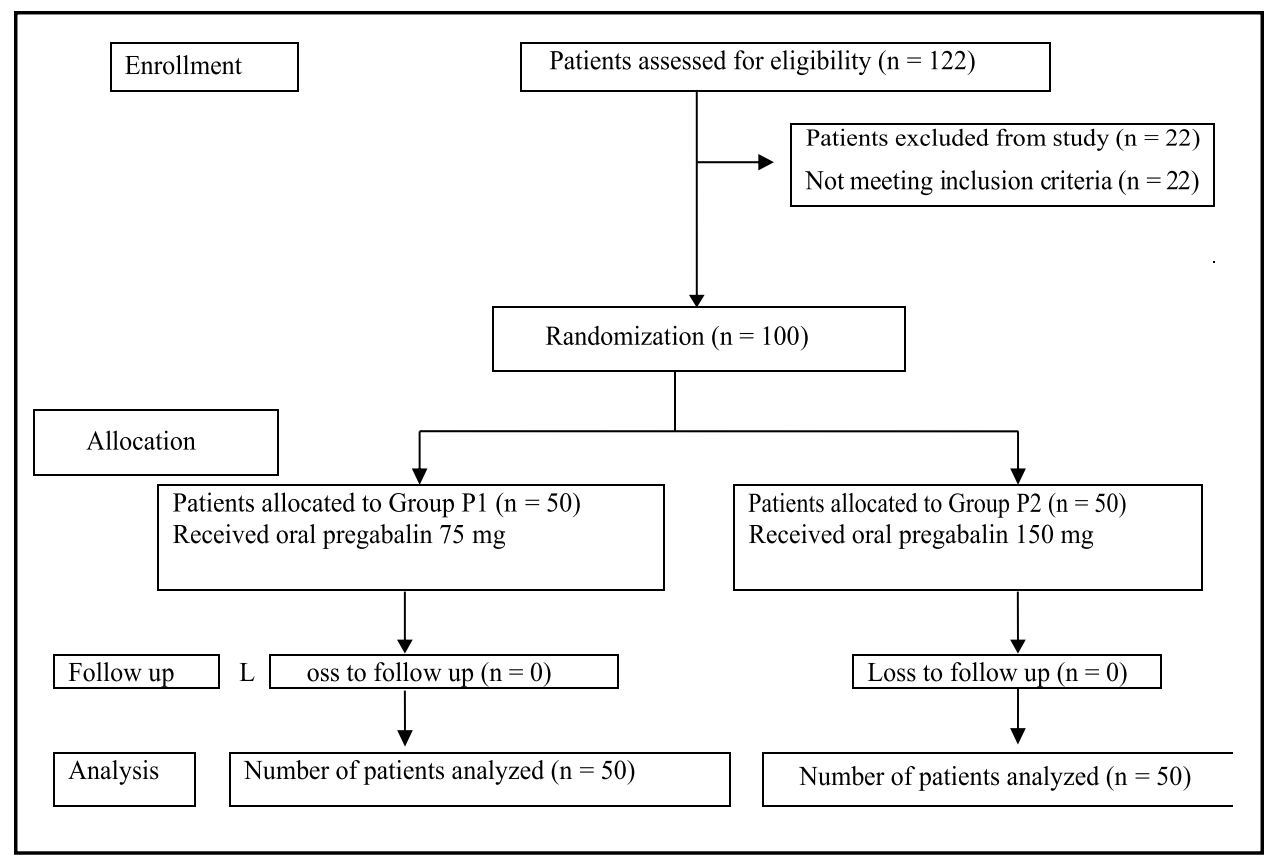

Figure 1: Consort flow diagram

the study of Rastogi B et al., ${ }^{17}$ who compared placebo (Group I), pregabalin $75 \mathrm{mg}$ (Group II) and pregabalin $150 \mathrm{mg}$ (Group III), given $1 \mathrm{~h}$ before induction of anesthesia and they observed that HR was increased in all three groups immediately after laryngoscopy and intubation, but the increase was least in pregabalin $150 \mathrm{mg}$ (Group III), which was statistically not significant $(\mathrm{p}>0.05)$ while statistically significant attenuation of MAP was seen in pregabalin $150 \mathrm{mg}$ (Group III). It might be due to effective analgesia and adequate sedation by pregabalin $150 \mathrm{mg}$. A previous study by Gupta $\mathrm{K}$ et al. ${ }^{18}$ showed statistically significant attenuation of MAP with oral pregabalin $150 \mathrm{mg} 1 \mathrm{~h}$ prior to surgery with no significant change in HR. Our findings are markedly different from previous study by Eren et al., ${ }^{19}$ in which there was a significant decrease in HR and MAP in pregabalin $150 \mathrm{mg}$ after laryngoscopy and intubation. The probable reason might be use of different premedication in their study. However, in contrast Meena $\mathrm{R}$ et al. ${ }^{20}$ reported a significant increase in $\mathrm{HR}$ after airway instrumentation in pregabalin $150 \mathrm{mg}$ group.

A significant attenuation in mean SBP, DBP and MAP were observed in Group P2 immediately after intubation, at 1 and $3 \mathrm{~min}$. The mean SBP, DBP and MAP were returned to their baseline valuesignificantly earlier in Group P2 (3 min) when compared to Group P1 (5min). Our results are similar to the study conducted by Bhandari $\mathrm{G}$ et al. ${ }^{21}$ and Chakraborty $\mathrm{R}$ et al., ${ }^{22}$ who compared oral pregabalin $150 \mathrm{mg}$ and placebo received $1 \mathrm{~h}$ prior to surgery and they observed a significant attenuation of SBP, DBP and MAP in pregabalin $\quad 150 \quad \mathrm{mg}$ group following la r y n g o s c o p y and endotracheal intubation. Although increase in $\mathrm{HR}$ was less in pregabalin group during laryngoscopy and intubation but it was not statistically significant. Salman et al., ${ }^{23}$ compared oral pregabalin $150 \mathrm{mg}$ and placebo received $1 \mathrm{~h}$ prior to surgery showed statistically $\mathrm{s}$ i g n i f i c a $\mathrm{n} \mathrm{t}$ attenuation in SBP, DBP and MAP in pregabalin $150 \mathrm{mg}$ group after induction, at intubation and 1 min post intubation. No significant difference in HR was noted at any time interval between two groups.Allu $\mathrm{H}$ et al. ${ }^{24}$ also observed the similar trends of changes in SBP, DBP and MAP who compared pregabalin $150 \mathrm{mg}$ and placebo given $1 \mathrm{~h}$ prior to induction of anesthesia for evaluating hemodynamic pressor response. Similarly, Waiker C et al. ${ }^{25}$ compared pregabalin 150, gabapentin $900 \mathrm{mg}$ and clonidine 200 $\mu \mathrm{g}$, who received oral drugs $90 \mathrm{~min}$ before induction of general anesthesia and hemodynamic parameters such as HR and blood pressures were noted at various time intervals. They reported a significant attenuation in MAP by pregabalin than others while mean HR was attenuated by clonidine group significantly.

The induction agents used in different studies may influence the results of techniques to lessen the hemodynamic pressor responses to laryngoscopy and endotracheal intubation. We have used propofol as an induction agent which may cause hypotension and bradycardia thus hypertension and tachycardia resulting from laryngoscopy and intubation may have been attenuated by propofol in both groups.

In our study, it was shown that oral pregabalin $150 \mathrm{mg}$ given $1 \mathrm{~h}$ before induction of anesthesia attenuated the hemodynamic pressor response to laryngoscopy and endotracheal intubation. It might be due to adequate sedation, anxiolysis and analgesia. Although the hemodynamic pressor response was attenuated with pregabalin in both groups which was found to statistically significant but these changes remained in clinically acceptable range (no clinical significance). The effect of pregabalin on the hemodynamic response to laryngoscopy and tracheal intubation might be explained by its inhibitory effects on membrane 


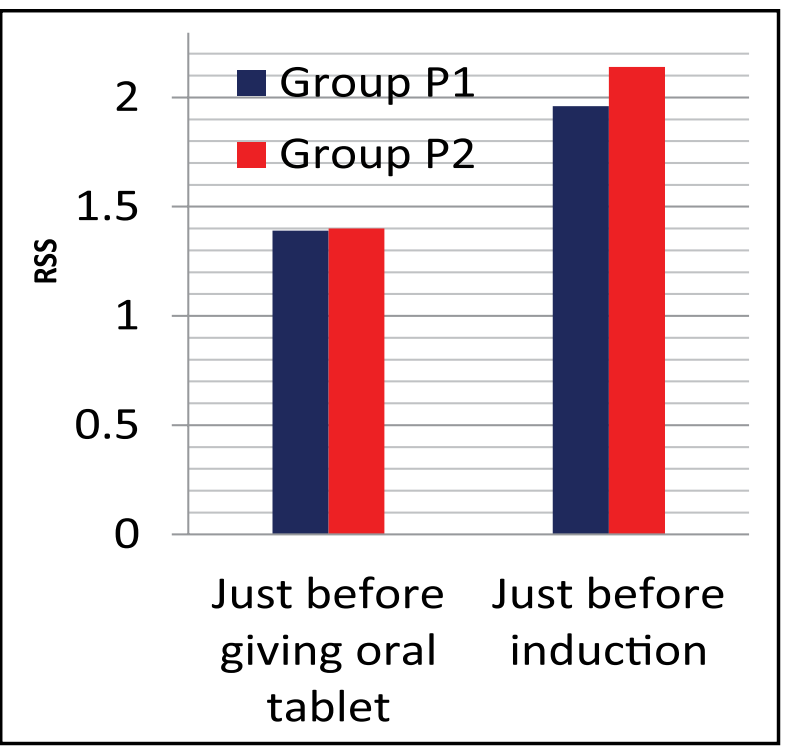

Figure 2: Comparison of mean sedation score (RSS) in two groups

voltage gated calcium channels. Pregabalin, binds potently and selectively to the alpha 2 delta subunit of hyper-excited voltage gated calcium channels. It modulates the release of excitatory neurotransmitters in hyper-excited neurons, restoring them to normal physiologic state, by reducing calcium influx at nerve terminals. ${ }^{26}$ The increased hemodynamic pressor response in pregabalin $75 \mathrm{mg}$ group may be due to inadequate sedation, anxiolysis and analgesia.

The level of sedation was comparable to previous studies; higher sedation scores were acceptable in Group P2 i.e. arousable sedation. . $^{17,18,21,22}$ Increased perioperative sedation has been observed in a dose related fashion at higher doses $(\geq 300 \mathrm{mg}){ }^{27}$

No significant complications occurred after the use of oral pregabalin in our study. None of the patients experienced nausea and / or vomiting or respiratory depression during our study.

\section{LIMITATIONS}

Although we restricted our laryngoscopy period to $<20 \mathrm{sec}$, we did not measure the duration of laryngoscopy; also the intubating anesthesiologist was not the same in all patients. We did not measure the stress mediators such as endogenous plasma catecholamines or cortisone. The frequency of postoperative sedation or delayed emergence from general anesthesia in both groups was not measured.

\section{CONCLUSION}

The results of our study prove that $150 \mathrm{mg}$ of oral pregabalin, when used as premedication $60 \mathrm{~min}$ prior to induction of anesthesia is more effective than 75 $\mathrm{mg}$ of pregabalin in terms of significant attenuation of hemodynamic pressor response to laryngoscopy and endotracheal intubation, with acceptable levels of sedation and minimal side effects.

Acknowledgement: Nil

Conflicts of Interest: None

Authors' contribution:

VP: Concept, Study design, Literature review, Manuscript review and proof reading

RLY: Literature search, Data collection and interpretation, Manuscript preparation

SKS: Literature review, Data interpretation, Manuscript review, editing and proof reading

NJ: Study design, Manuscript review

MS: Manuscript review 


\section{REFERENCES}

1. Russell WJ, Morris RG, Frewin $\mathrm{DB}$, Drew SE. Changes in plasma catecholamine concentrations during endotracheal intubation. $\mathrm{Br} \mathrm{J}$ Anaesth. 1981;53:837-39. [PubMed] DOl: $\underline{10.1093 / \mathrm{bja} / 53.8 .837}$

2. King BD, Harris LC, Griefenstein FE, Elder JD, Dripps RD. Reflex circulatory responses to direct laryngoscopy and tracheal intubation performed during general anesthesia. $\mathrm{Br} J$ Anaesth. 1951; 12:556-66. [PubMed] DOI: 10.1097/00000542-195109000$\underline{00002}$

3. Fox EJ, Sklar GS, Hill CH, Villanoeva $\mathrm{R}$, King BD. Complication related to pressor response to endotracheal intubation. Anesthesiology. 1977;47:524-5. [PubMed] DOl: 10.1097/00000542-197712000$\underline{00013}$

4. Kanchi M, Nair HC, Bankal S, Murthy $\mathrm{K}$, Murugesan C. Hemodynamic response to endotracheal intubation in coronary artery disease. Indian J Anesth. 2011; 55:260-5. [PubMed] DOl: $10.4103 / 0019-5049.82673$

5. Shribman AJ, Smith G, Achola KJ. Cardiovascular and catecholamine response to laryngoscopy with and without tracheal intubation. $\mathrm{Br} J$ Anesth. 1987;59:295-9. [PubMed] DOI: $10.1093 / \mathrm{bja} / 59.3 .295$

6. Stoelting RK. Circulatory changes during direct laryngoscopy and tracheal intubation: Influence of duration of laryngoscopy with or without prior lignocaine. Anaesthesiology. 1977:47(4):381-3. [PubMed] DOI: 10.1097/00000542197710000-00012

7. Dahlgren N, Messeter K. Treatment of stress response to laryngoscopy and intubation with fentanyl. Anesthesia. 1981:36(11):1022-6. [PubMed] DOI: $\quad$ 10.1111/j.1365-2044.1981. tb08676.x

8. Coleman AJ, Jordan C. Cardiovascular responses to anaesthesia. Influence of beta-adrenoreceptor blockade with metoprolol. Anaesthesia 1980;35(10):972-978. [PubMed]
DOI: $\quad 10.1111 / \mathrm{j} .1365-2044.1980$. tb04995.x

9. Puri GD, Batra YK. Effect of nifedipine on cardiovascular responses to laryngoscopy and intubation. $\mathrm{Br}$ $J$ Anaesth. 1988;60(5):579-81. [PubMed] D0I: 10.1093/bja/60.5.579

10. Fassoulaki $A$, Kaniaris $P$. Intranasal administration of nitroglycerine attenuates the pressor response to laryngoscopy and intubation of the trachea. Br J Anaesth. 1983;55(1):4952. [PubMed] DOI:10.1093/ bja/55.1.49

11. Reddy SV, Balaji D, Ahmed SN. Dexmedetomidine versus esmolol to attenuate the hemodynamic response to laryngoscopy and tracheal intubation: A randomized double-blind clinical study. Int J Appl Basic Med Res. 2014;4(2):95-100. [PubMed] DOI: $10.4103 / 2229-516 X .136788$

12. Talebi $H$, Nourozi $A$, Fateh $S$, Mohammadzadeh $A$, EghtesadiAraghi $P$, Jabbari S, Kalantarian $M$. Effects of oral clonidine premedication on haemodynamic response to laryngoscopy and tracheal intubation: a clinical trial. Pak J Biol Sci. 2010;13(23):1146-50. [PubMed] DOI: $10.3923 /$ pibs.2010.1146.1150

13. GajrajNM.Pregabalin:itspharmacology and use in pain management. Anesth Analg. 2007;105(5):180515. [PubMed] DOI:10.1213/01. ane.0000287643.13410.5e

14. White PF, Tufanogullari B, Taylor J, Klein K. The effect of pregabalin on preoperative anxiety and sedation levels: a dose ranging study. Anesth Analg. 2009;108(4):11405. [PubMed] DOI: $\underline{10.1213 /}$ ane.0b013e31818d40ce

15. Walker R. ASA and CEPOD scoring. Update in Anaesthesia 2002;14:1. [Free Full Text]

16. Stawicki SP. Sedation scales: Very useful, very underused. OPUS12 Scientist. 2007;1(2):10-2. [Eree Full Text]

17. Singh $G$, Kaur $H$, Aggarwal $S$, Sharda G, Singh A, Jha A, Aggarwal
H. Intravenous dexmedetomidine vs. lignocaine in attenuating the hemodynamic responses during laryngoscopy and endotracheal intubation: a randomized double blind study. Anaesth Pain Intensive Care. 2017;21(2):181-6. [Free Full Text]

18. Gupta K, Bansal P, Gupta PK, Singh YP. Pregabalin premedication - A new treatment option for hemodynamic stability during general anesthesia: a prospective study. Anesth Essays Res. 2011;5(1):57-62. [PubMed] DOI: 10.4103/0259-1162.84192

19. Eren G, Kozanhan B, Hergunsel 0 . Pregabalin blunts cardiovascular response to laryngoscopy and tracheal intubation. Turkey Clinical J Anest I Reanim. 2009;7(2):82-7. [Eree Full Text]

20. Meena R, Meena K, Prakash S. Study of attenuation of cardiovascular response during laryngoscopy and intubation using two different doses of pregabalin as premedication in controlled hypertensive patients-A RCT. J Anesth Clin Ress 2016;7:607. DOI: $10.4172 / 2155-6148.1000607$

21. Bhandari G, Mitra S, Shahi KN, Rani A, Chauhan A. Pre-emptive use of oral pregabalin attenuates the pressor response of laryngoscopy and endotracheal intubation: A double blinded randomized placebo controlled study. Ann Int Med Dent Res. 2016;2(3):110-4. DOI: 10.21276/ aimdr.2016.2.3.28

22. Chakraborty $R$, Jain $R$, Sharma $R$. Evaluation of the efficacy of pre-operative oral pregabalin in attenuating haemodynamic response to laryngoscopy and intubation and on post-operative pain in patients undergoing elective surgery under general anaesthesia. Indian $\mathrm{J}$ Clin Anaesth. 2016;3(3):423-30. DOI: 10.5958/2394-4994.2016.00071.8

23. Salman E, Celik C, Candan S. Premedication with single dose pregabalin $150 \mathrm{mg}$ attenuates hemodynamic response to laryngoscopy and endotracheal 


\section{original research}

intubation. 2012;1:297. D0I: 10.4172/ scientificreports.297

24. Allu H, Kulkarni M, Dinesh E. Study to determine the effect of oral pregabalin premedication on haemodynamic response to laryngoscopy, intubation and carbon dioxide insufflation during laparoscopic cholecystectomy. Sri Lankan J Anaesth. 2019;27(1):8-14. DOl: 10.4038/slja.v27i1.8341

25. Waikar C, Singh J, Gupta D, Agrawal
A. Comparative study of oral gabapentin, pregabalin, and clonidine as premedication for anxiolysis, sedation, and attenuation of pressor response to endotracheal intubation. Anesth Essays Res. 2017;11(3):55860. [PubMed] DOI: 10.4103/aer. AER $34 \quad 17$

26. Kavoussi R. Pregabalin: from molecule to medicine. Eur Neuropschycopharmacol. $\quad 2006 ; 16$
Suppl 2:S128-3. [PubMed] DOl: 10.1016/.j.euroneuro.2006.04.005

27. Saxena A, Gupta P, Chaudhary L. Effect of pregabalin premedication on the laryngoscopic response and intraoperative hemodynamic variables in laparoscopic cholecystectomy: a randomized comparison of two doses. Indian J Sci Stud. 2016;4(5):75-80. DOI: $\underline{10.17354 / \mathrm{ijss} / 2016 / 433}$

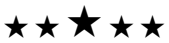

